\title{
КАДРОВЫЕ ПРОБЛЕМЫ
} РАДИОЭЛЕКТРОННОЙ ОТРАСЛИ РЕЗУЛЬТАТЬІ

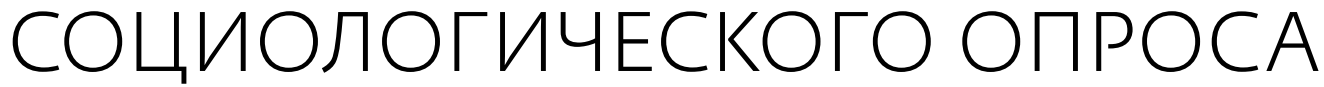

\author{
А.Фомина, д.э.н. ${ }^{1}$
}

УДК 311.42

BAK 05.27.06

Непростая ситуация с кадрами в российской радиоэлектронной промышленности регулярно становится предметом обсуждений. Однако, несмотря на очевидность многих проблем в этой сфере, таких как нехватка молодых кадров, недостаточный уровень подготовки выпускников вузов и несоответствие зарплат специалистов ожидаемому уровню, без количественной оценки и понимания взаимосвязи различных факторов эффективные пути решения этих проблем выявить не представляется возможным. Поэтому необходимость масштабного комплексного исследования кадровой ситуации в радиоэлектронной отрасли назрела уже достаточно давно.

ыявлению существующих кадровых проблем в радиоэлектронной промышленности было посвящено крупное исследование, проведенное ЦНИИ "Электроника" совместно с отраслевым журналом "ЭЛЕКТРОНИКА: Наука, Технология, Бизнес" и компанией "ЭКОПСИ Консалтинг", краткий анализ результатов которого приводится в настоящей статье. Результаты этого проекта могут стать основой для создания эффективных мер по предотвращению старения отрасли и привлечению в данную сферу молодых и талантливых специалистов, а также для сближения программ вузов с объективными потребностями действующих организаций.

ЦниИ "Электроника", генеральный директор.

\section{ОБ ИССЛЕДОВАНИИ}

Исследование было инициировано ЦниИ "Электроника". В качестве партнеров проекта выступили ведущий отраслевой научно-технический журнал "ЭЛЕКТРОНИКА: Наука, Технология, Бизнес" и крупнейшая российская компания в сфере управления персоналом "ЭКОПСИ Консалтинг".

Исследование проходило в форме опроса с использованием специально разработанной анкеты, которая направлялась руководителям организаций радиоэлектронной промышленности.

В опросе приняли участие более 500 организаций радиоэлектронного комплекса: от совсем небольших компаний до крупнейших концернов и холдингов. Примерно в 60\% организаций, которые приняли 


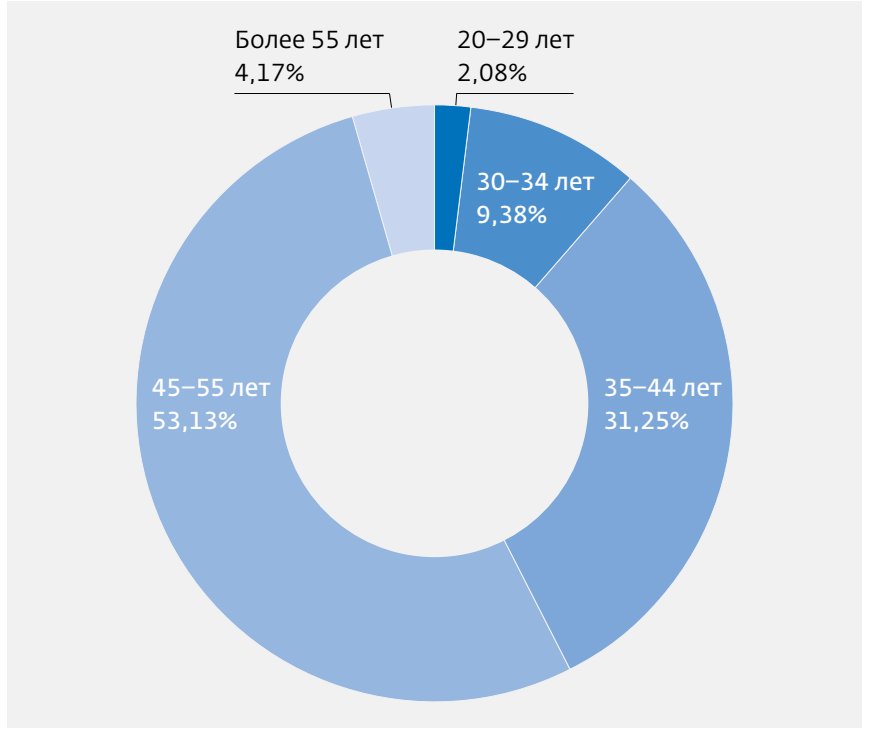

Рис.1. Средний возраст сотрудников организаций

участие в исследовании, численный состав сотрудников составляет свыше 300 человек, в 30\% - количество сотрудников находится в диапазоне от 100 до 300 человек. Оставшиеся организации являются небольшими, количество сотрудников в которых не превышает 100 человек.

\section{РЕЗУЛЬТАТЫ ОПРОСА}

В отношении среднего возраста сотрудников опрос показал следующее распределение: более половины участников опроса (53\%) указали возрастной диапазон от 45 до 55 лет, около одной трети - от 35 до 44 лет. Лишь немногим более 10\% респондентов оценили средний возраст своих работников от 20 до 34 лет. В оставшемся числе компаний этот показатель составляет более 55 лет (рис.1).

Если сравнить данные по возрастному распределению в отрасли с данными Росстата, охватывающими общество в целом, можно увидеть несколько существенных разрывов. Первый разрыв наблюдается в группе 20-29 лет: в радиоэлектронную отрасль идет всего около $2 \%$ населения, в то время как доля этой группы в обществе составляет почти четверть. Далее, в группах 30-34 и 35-44 года ситуация выравнивается. Следующий крупный разрыв виден в группе 45-55 лет, К которой относится более $50 \%$ сотрудников предприятий отрасли, тогда как в целом в обществе данная группа составляет немногим более 20\%.

Нехватку молодых специалистов испытывают более половины опрошенных организаций; в то же время руководители 40\% опрошенных компаний сочли ситуацию с молодыми кадрами в своих организациях в норме и нехватку в таких специалистах они не

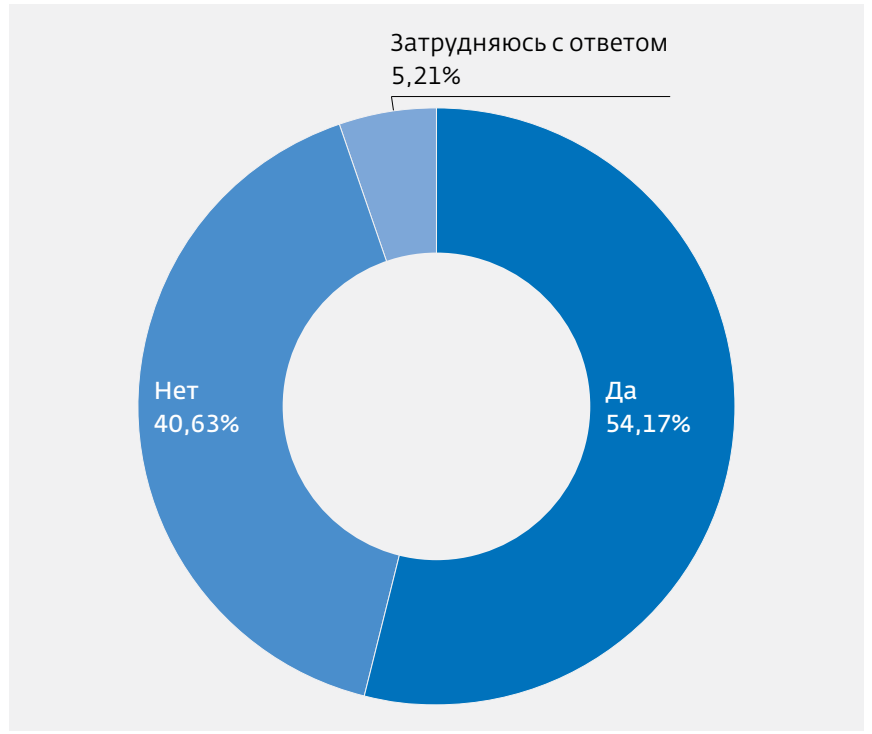

Рис.2. Распределение ответов на вопрос:

"Испытывает ли ваше предприятие, по вашему мнению, нехватку в молодых специалистах?"

испытывают (рис.2). Последний показатель выглядит достаточно странным, учитывая, что в возрастном распределении сотрудников радиоэлектронной отрасли группа 20-29 лет составляет всего лишь 2\%. Этот показатель существенно меньше, чем в других, привлекательных для молодежи областях. Данные цифры указывают на формирующуюся в отрасли "демографическую яму". Но пока ситуация не очень критична, так как основную массу сотрудников составляют специалисты от 35 до 55 лет, которые находятся еще в хорошем трудоспособном состоянии и меньше ориентированы на поиск лучшего работодателя [1]. Тем самым, данная возрастная группа является наиболее стабильной и удобной для управленцев на предприятиях. Еще одним отличительным пунктом является то, что работники, относящиеся к данной возрастной группе, являются готовыми специалистами и не требуют больших ресурсов на обучение, подготовку или повышение квалификации. Проблемы неизбежно начнутся на горизонте 10-15 лет, но в текущий момент респонденты, по-видимому, об этом не задумываются.

Среди категорий специальностей в отрасли по результатам опроса наибольшая нехватка молодых специалистов относится к разработчикам: эту категорию указали как наиболее критичную с данной точки зрения более 60\% опрошенных (рис.3). Также существует большая потребность в молодых кадрах в производстве радиоэлектронной продукции (чуть более $30 \%$ респондентов).

Более половины респондентов (около 53\%) считают свои организации привлекательными для молодых 


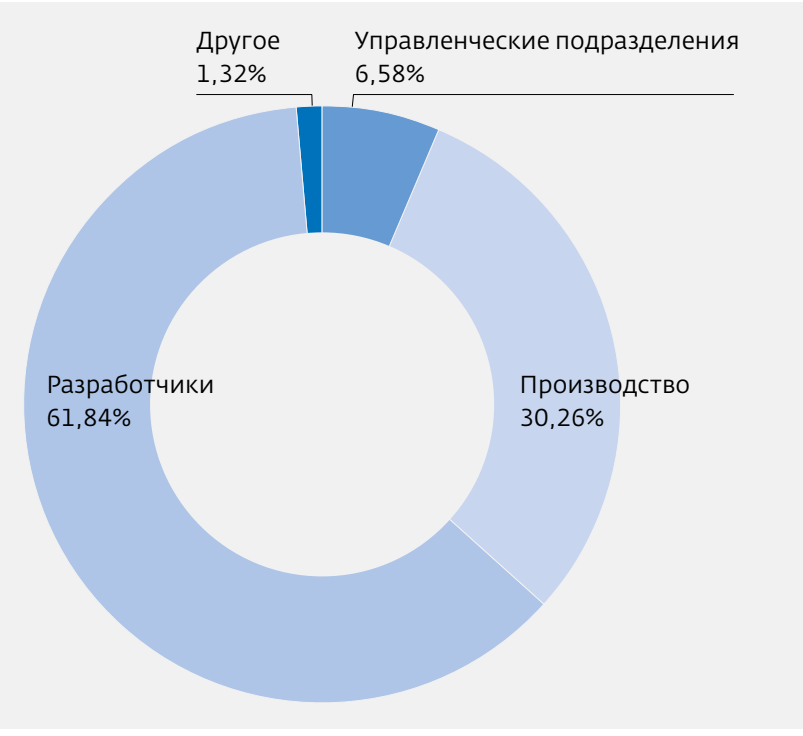

Рис.3. Распределение ответов на вопрос: "Какие позиции в структуре вашего предприятия в большей степени испытывают нехватку молодых кадров?"

специалистов. Четверть из числа опрошенных затруднились с ответом на этот вопрос. Чуть меньше четверти указали, что условия труда в их организациях не являются привлекательными для молодых кадров (рис.4).

Продолжая тему нехватки молодых специалистов, логично определить факторы, которые влияют на привлекательность организаций для трудоустройства молодежи. Примерно треть респондентов в качестве

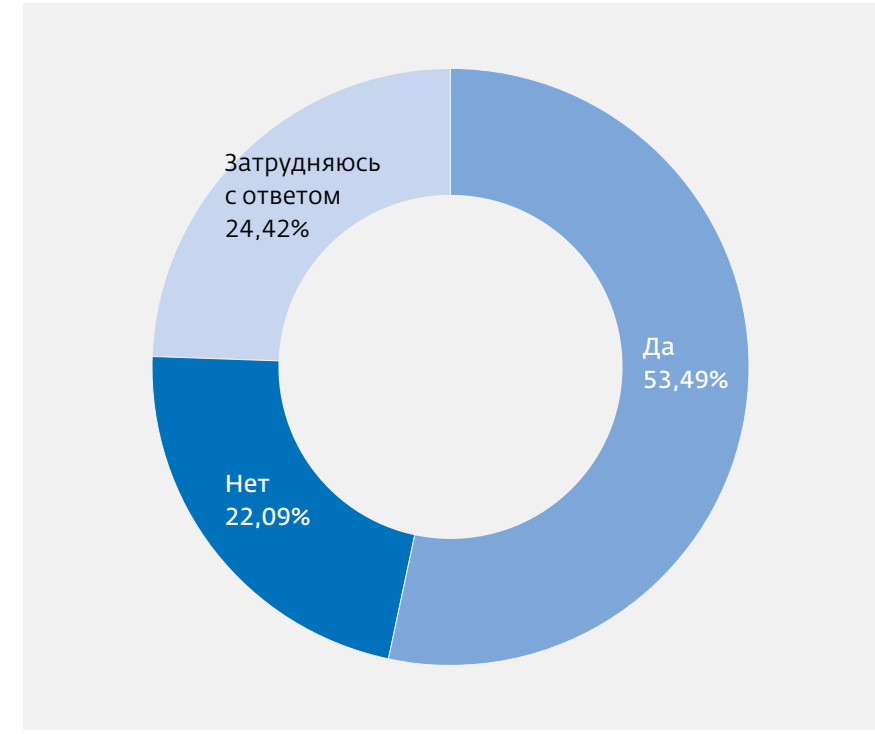

Рис.4. Распределение ответов на вопрос: "Является ли трудоустройство на вашем предприятии, по вашему мнению, привлекательным для молодых специалистов?"

основного критерия указала заработную плату. Второе место (с разницей в несколько процентов) занимают карьерные возможности. Примерно такой же процент респондентов указал значимым фактором репутацию организаций. На четвертом месте примерно с 14,5\% значится хороший социальный пакет (рис.5).

Если оценить мотивационные факторы в разрезе разработчиков и тех, кто занят непосредственно на
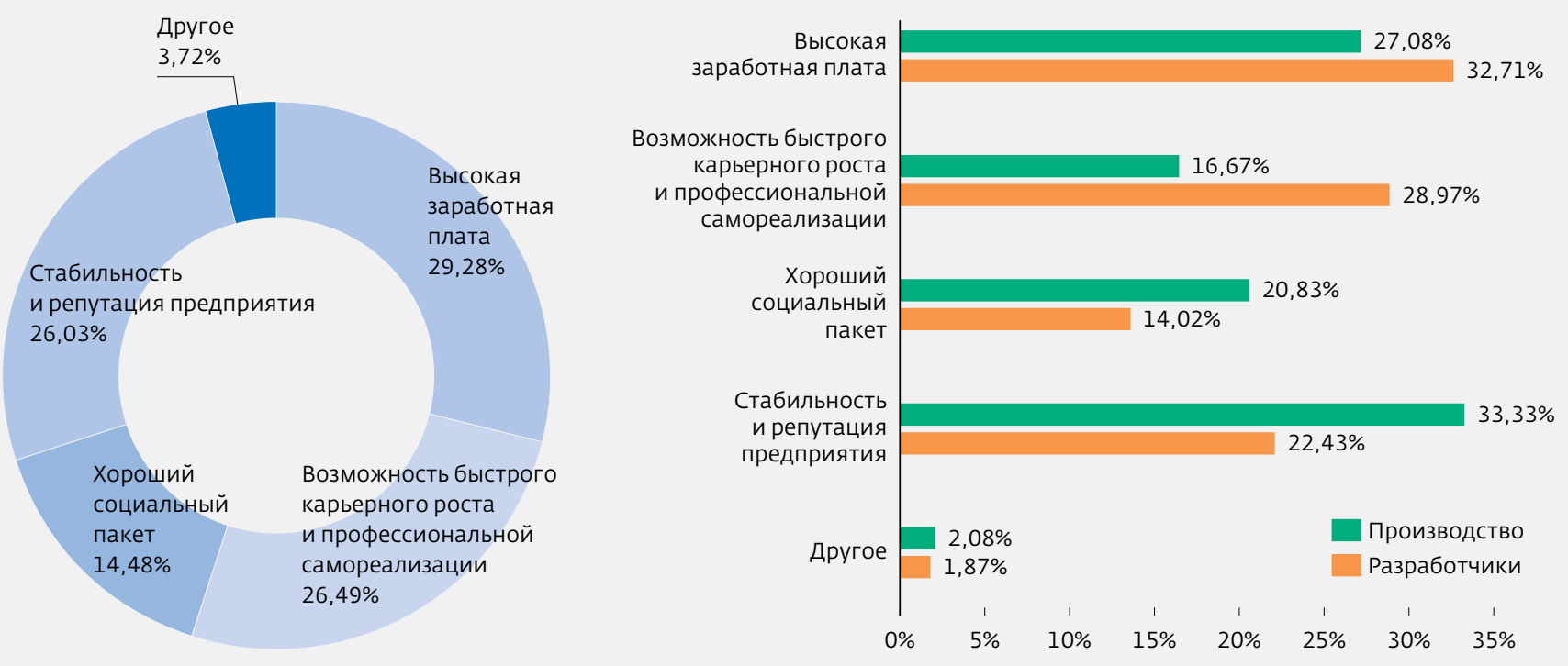

Рис.5. Распределение ответов на вопрос: "Что, по вашему мнению, может привлечь квалифицированного молодого специалиста для трудоустройства на ваше предприятие?" 


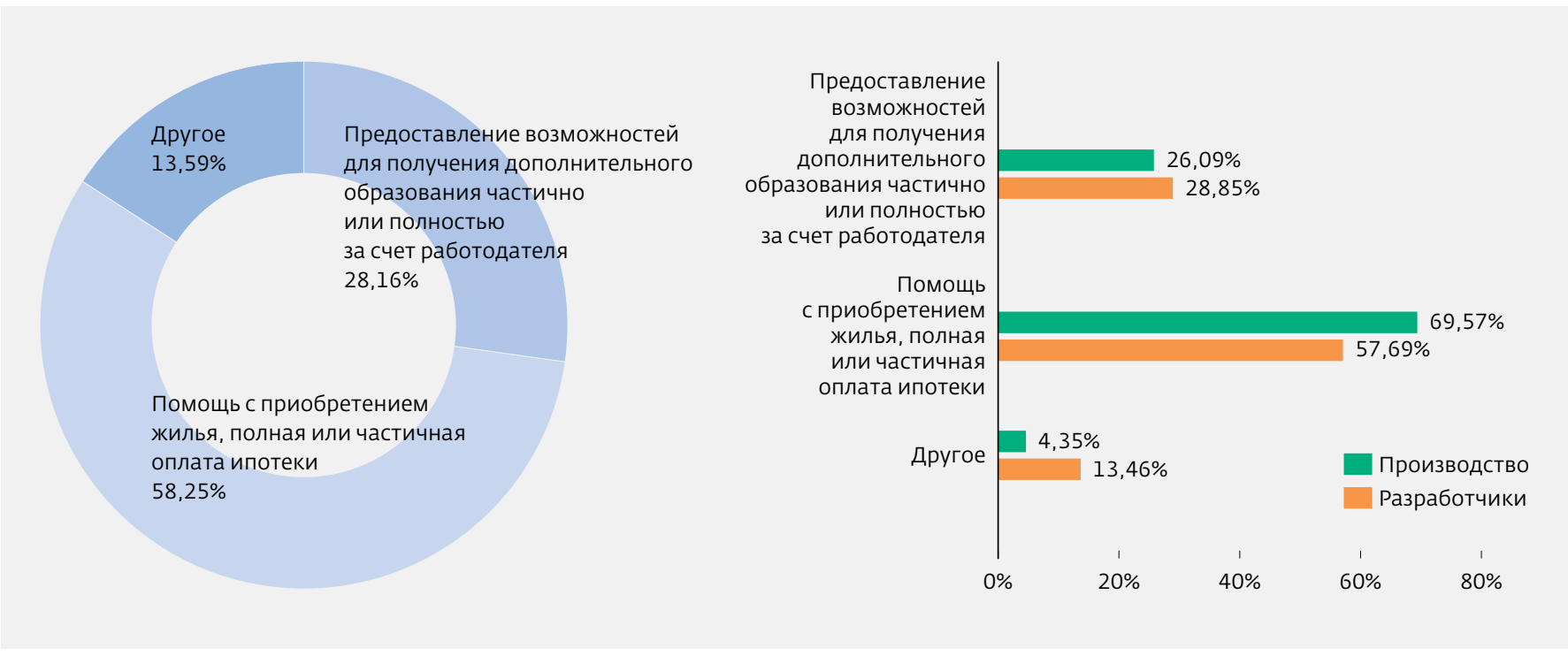

Рис.6. Распределение ответов на вопрос о том, что могло бы являться хорошим мотивирующим инструментом для привлечения молодых кадров

производстве, то можно сказать, что, по мнению участников опроса, высокий уровень оплаты труда весьма значим для обеих категорий специалистов. Возможность быстрого карьерного роста в большей степени интересует разработчиков, чем производственников (разница больше 10\%). Хороший социальный пакет имеет практически одинаковое значение для обеих групп (разница около 5\%, как и для фактора заработной платы). В то же время стабильность и репутация предприятия является более значимым фактором именно для производственников (разница более 10\%). Прочие факторы имеют гораздо меньшее значение для обеих групп.

В части критериев привлекательности работодателя исследователи выделили такие мотивирующие инструменты, как возможность дополнительного образования за счет организации и помощь с приобретением жилья, в том числе полная или частичная оплата ипотеки. Около 58\% респондентов указали жилищный вопрос в качестве основного, а около 28\% - возможность повышения образовательного уровня (рис.6).

В разрезе разделения по специальностям возможность получения дополнительного образования является более мотивирующим фактором именно для разработчиков, что вполне очевидно, но разница с производственниками не принципиальная (всего около 2-3\%). Помощь с приобретением жилья в большей степени имеет значение для специалистов-производственников (больше 10\% по сравнению с разработчиками).

Мотивирующие инструменты безусловно имеют большое значение для привлечения кадров, в частности молодых специалистов. Но почти в 40\% случаев, по мнению респондентов, они не используются, что является большим показателем, который мог бы оказаться значимым для решения части кадровых проблем. В то же время более чем в половине случаев данные мотивирующие инструменты на предприятиях в той или иной мере применяются (рис.7).

Если вернуться к вопросу уровня заработной платы, то, по мнению примерно 48\% респондентов, молодых людей может привлечь оклад от 30 до 49 тыс. руб. Почти столько же участников опроса считает, что

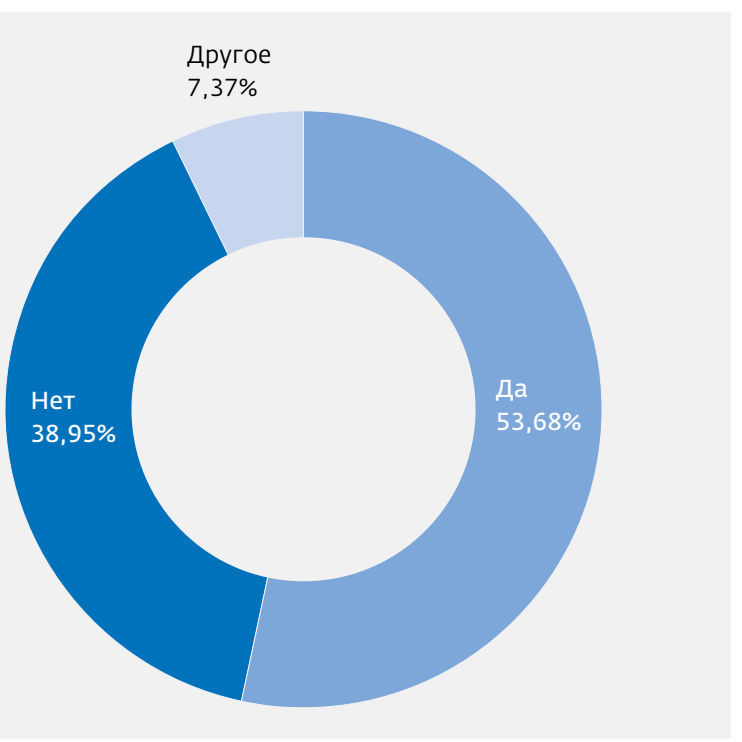

Рис.7. Распределение ответов на вопрос о том, применяются ли на предприятии мотивирующие инструменты для привлечения молодых кадров 


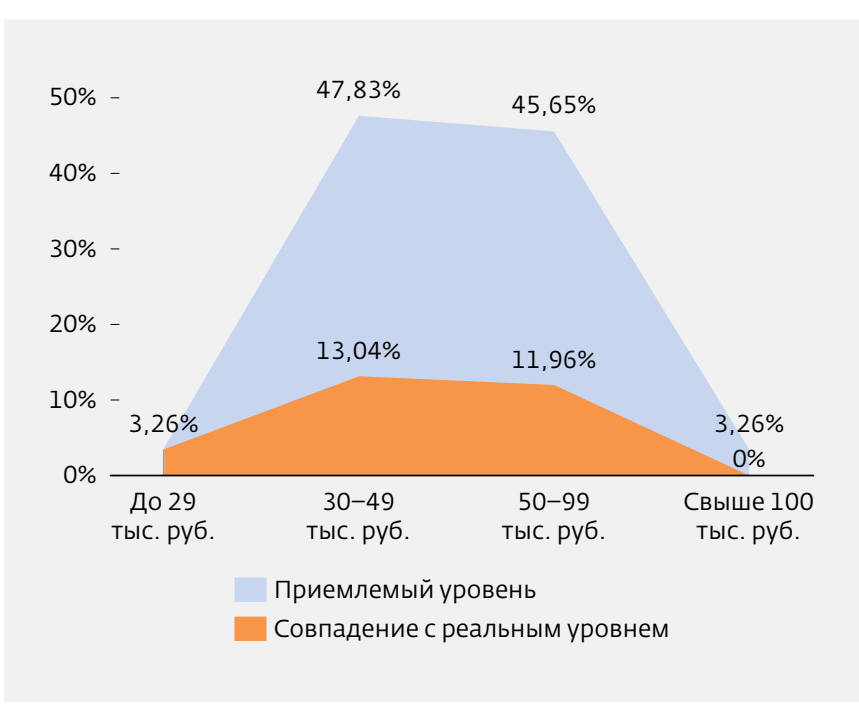

Рис.8. Совпадение реального уровня зарплаты молодых специалистов на фоне приемлемого по мнению респондентов

молодежь вправе рассчитывать на оклад от 50 до 99 тыс. руб. По 3,26\% респондентов указали на оклад до 29 и свыше 100 тыс. руб.

По факту же мы имеем несколько отличную картину по уровню дохода для молодых специалистов в организациях. Более чем в 40\% организаций такие специалисты зарабатывают до 29 тыс. руб. Примерно на таком же количестве предприятий их зарплата составляет от 30 до 49 тыс. руб. Более высоким уровнем дохода молодых специалистов (от 50 до 99 тыс. руб.) могут похвастаться менее 20\% респондентов.

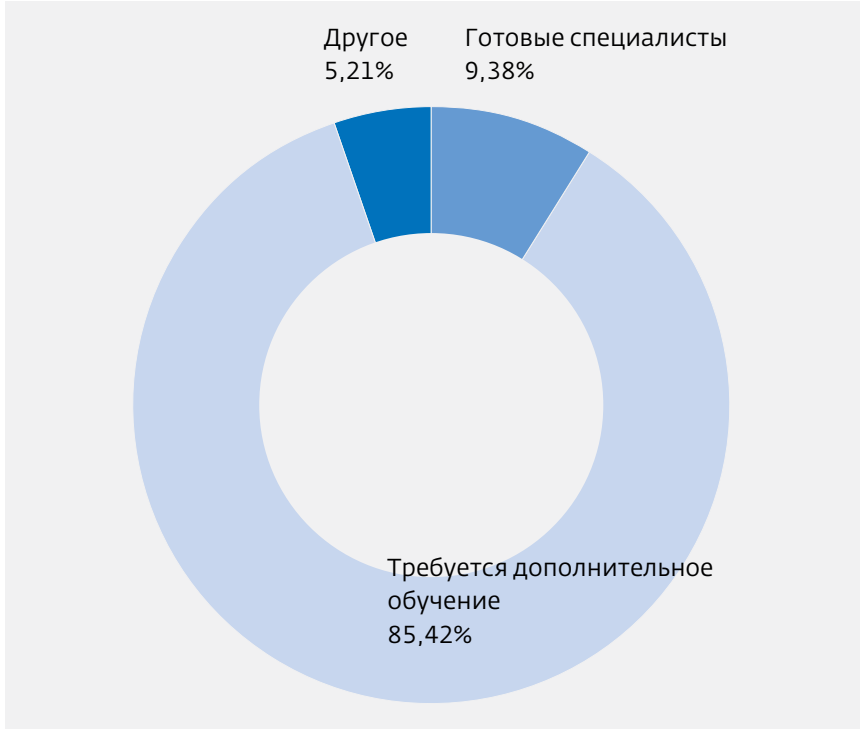

Рис.9. Характеристика молодых специалистов, приходящих на предприятия
Таким образом, отмечается огромный разрыв между тем уровнем заработной платы, который работодатель считает приемлемым, и тем, который сотрудник получает по факту. Считающиеся приемлемыми и реально выплачиваемые зарплаты совпадают в группе до 29 тыс. руб. чуть более чем у 3\% респондентов; в группе от 30 до 49 тыс. руб. - примерно у 13\% опрошенных организаций; в группе от 50 до 99 тыс. руб. - чуть менее чем у 12\% (рис.8).

Скорее всего, у таких расхождений может быть несколько причин. Во-первых, финансовые возможности организаций. А во-вторых, реальная оценка ценности сотрудников может быть ниже по причине неполной готовности молодого специалиста - об этом речь пойдет ниже.

Так, более 85\% респондентов отметили, что молодежь, которая приходит в организации, не удовлетворяет профессиональным требованиям работодателя. По мнению участников опроса, за редким исключением молодым специалистам требуется дополнительное обучение (рис.9).

Примерно также респонденты охарактеризовали общий уровень подготовки выпускников вузов. Подавляющее число участников исследования (более 88\%) указали на недостаточную подготовку (рис.10).

Таким образом, работодатель сталкивается с необходимостью подготовки таких специалистов за счет своих внутренних ресурсов, так как на смену стареющим кадрам нужно находить новые молодые резервы. Более 70\% респондентов в той или иной степени приходилось участвовать в подготовке молодых кадров в соответствии с внутренними потребностями (рис.11).

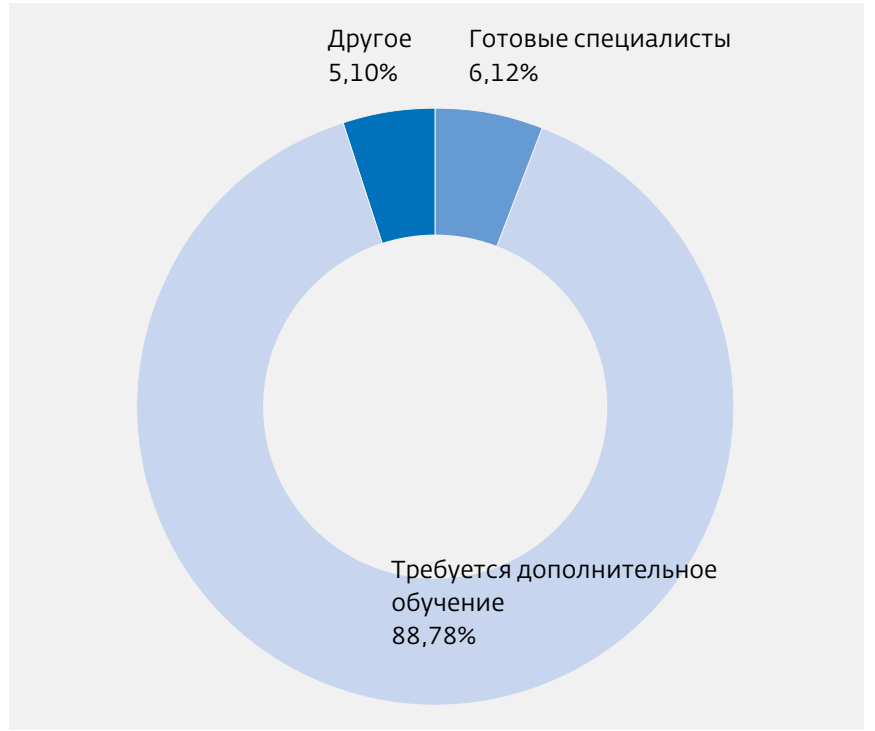

Рис.10. Уровень подготовки выпускников вузов 


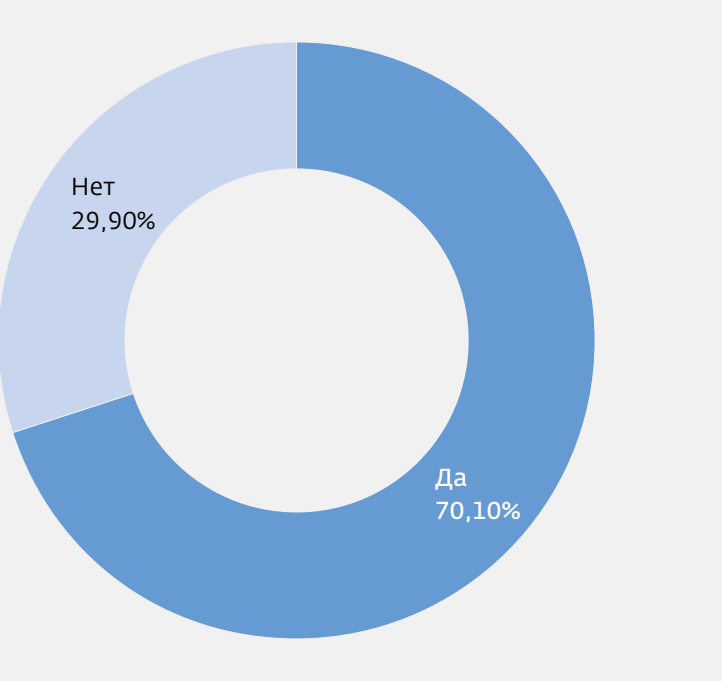

Рис.11. Ответ на вопрос: "Приходилось ли вам принимать участие в подготовке молодых специалистов на вашем предприятии?"

Безусловно, в некоторых организациях существует своя внутренняя узкая специфика, и таких узконаправленных специалистов найти практически невозможно. Из-за слишком узкой сегментации введение образовательных программ по этим специальностям в вузах может быть неоправданным. В таких случаях внутреннее обучение в организациях является необходимостью. Но более 20\% респондентов указывают на проблемы в дисциплинах, которые однозначно должны на необходимом уровне преподаваться в вузах (рис.12). Почти 80\% участников исследования согласились с тем, что дополнительное обучение в организациях напрямую связано с внутренней спецификой.

Что касается образовательных программ в вузах, то около 55\% респондентов в целом довольны подготовкой кадров (рис.13). Однако на прямое несоответствие образовательных программ в учебных заведениях указывает очень большое число участников исследования (почти 40\%). Что касается соответствия российского образования мировым стандартам, то российские вузы этим могут похвастаться по мнению лишь небольшого числа респондентов (чуть более 4\%).

В соответствии с сегодняшними реалиями дополнительное обучение все чаще требуется и уже работающим кадрам в отрасли. Более чем в 60\% организаций существуют программы повышения квалификации работающих сотрудников (рис.14).

Для повышения эффективности подготовки кадров необходимо постоянное сотрудничество организаций с вузами. Данная мера одинаково важна для обеих сторон. Более половины организаций старается брать студентов для прохождения стажировок (рис.15). Лишь 15\%

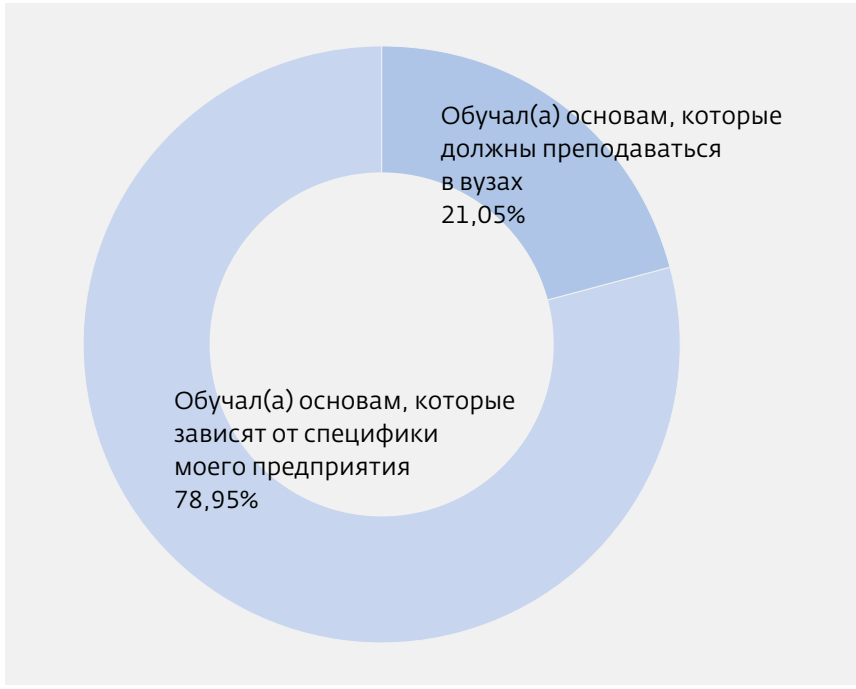

Рис.12. Характеристика участия в подготовке молодых специалистов

участников опроса могут похвастаться тем, что вузы участвуют в разработке программ с учетом специфики их организаций. Чуть больше 17\% стараются отслеживать лучших студентов для привлечения в дальнейшем в свои организации.

На основе данных опроса был составлен рейтинг вузов по количеству сотрудничающих с ними организаций (рис.16).

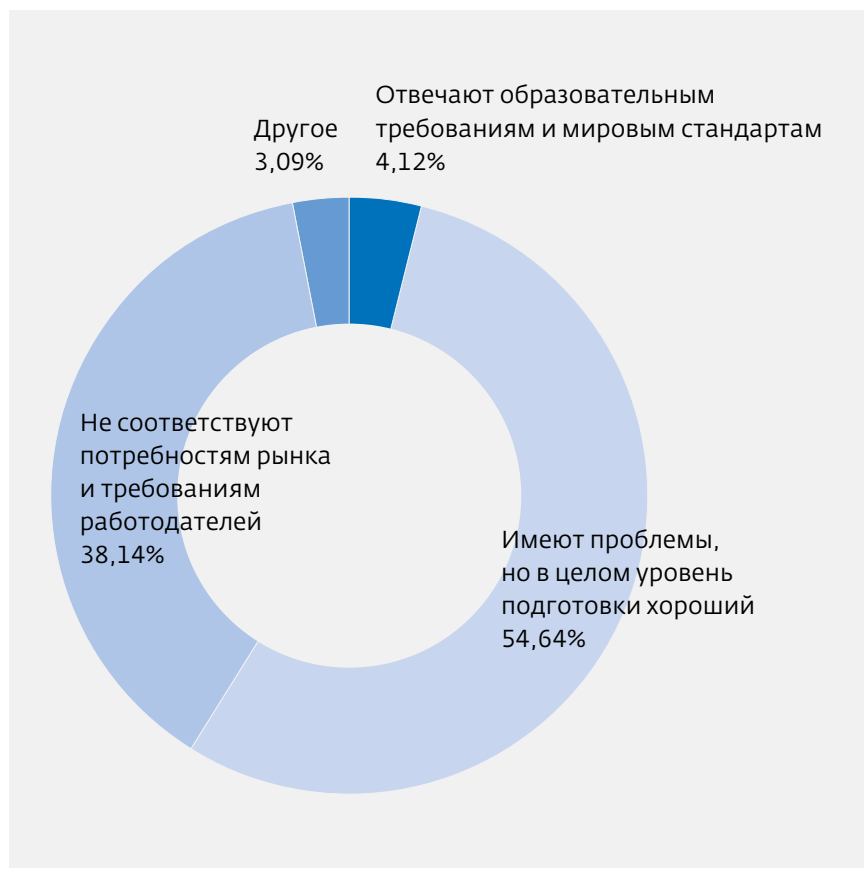

Рис.13. Характеристика образовательных программ вузов 


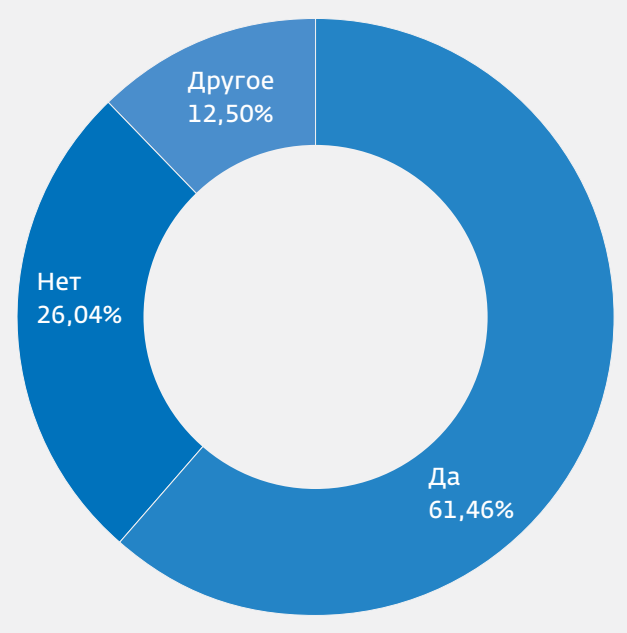

Рис.14. Наличие программ повышения квалификации в организациях

При этом исследователи обнаружили любопытные данные, которые показывают, что несмотря на налаженное сотрудничество с вузами и отбором лучших студентов, в большинство таких организаций реально устраиваются не более 10\% выпускников (рис.17). Этот показатель отметили почти 60\% респондентов. Четверть

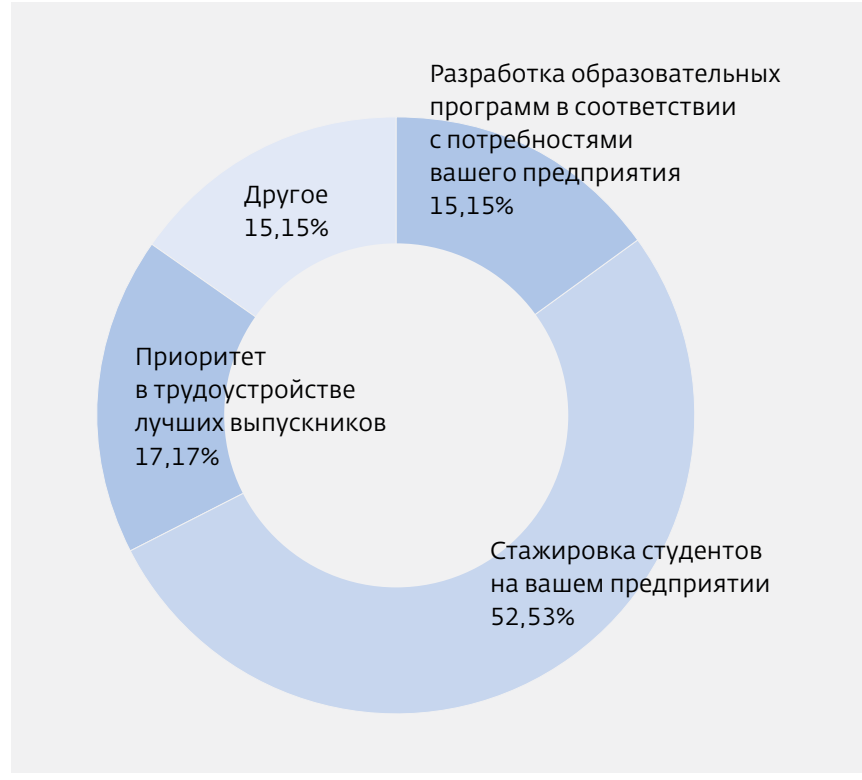

Рис.15. Сотрудничество с вузами

респондентов указала, что из партнерских вузов к ним приходят работать от 10 до 20\% выпускников. Более 30\% выпускников партнерских вузов устраивается к 1/10 части организаций радиоэлектронной промышленности.

Интересной частью опроса является блок о характеристике самой радиоэлектронной промышленности,

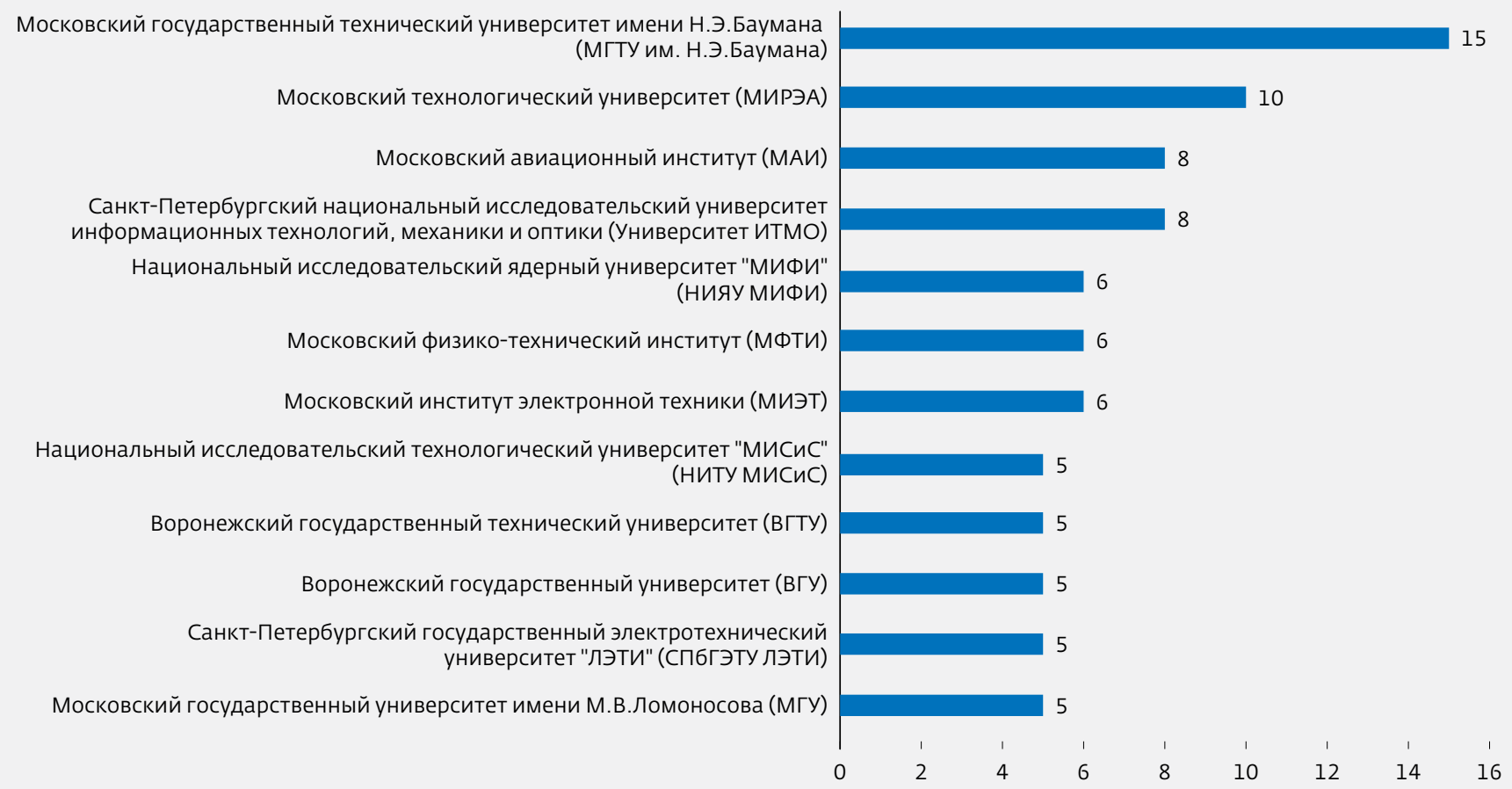

Рис.16. Рейтинг вузов на основе количества сотрудничающих организаций 


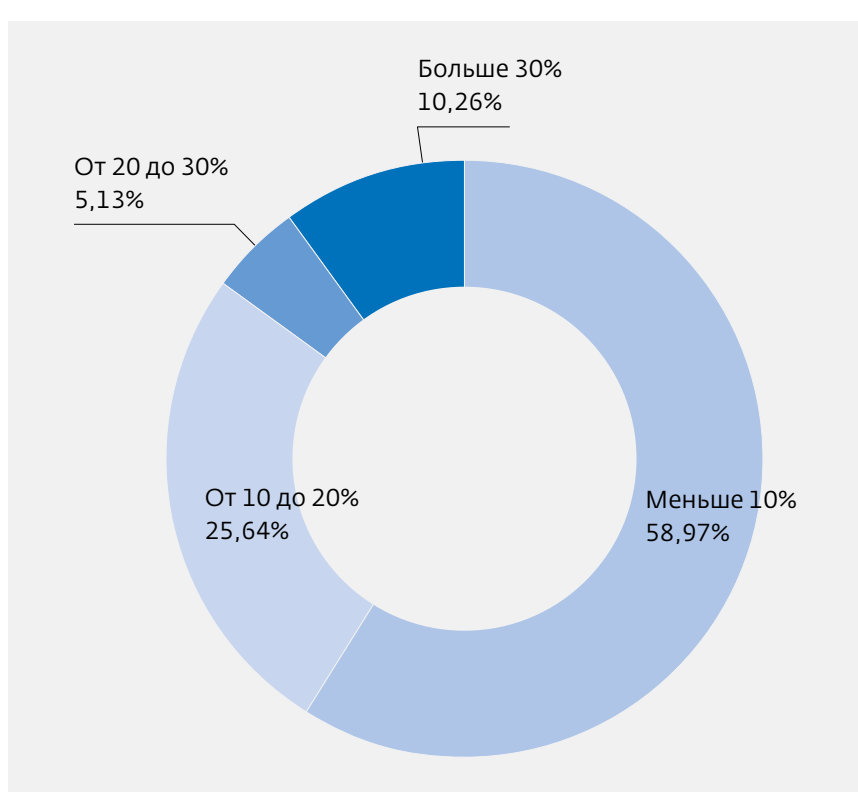

Рис.17. Процент выпускников вузов-партнеров, устраивающихся в соответствующую организацию

показывающий, как положение отрасли оценивают руководители организаций этого профиля (рис.18). Около 44\% участников опроса указали на то, что ситуация в данной отрасли хуже, чем в других отраслях. Примерно 20\% респондентов считают, что ситуация в отрасли отражает общую картину и в похожем положении могут находиться организации из других отраслей России. 35\% респондентов полагают, что ситуация в целом нормальная.

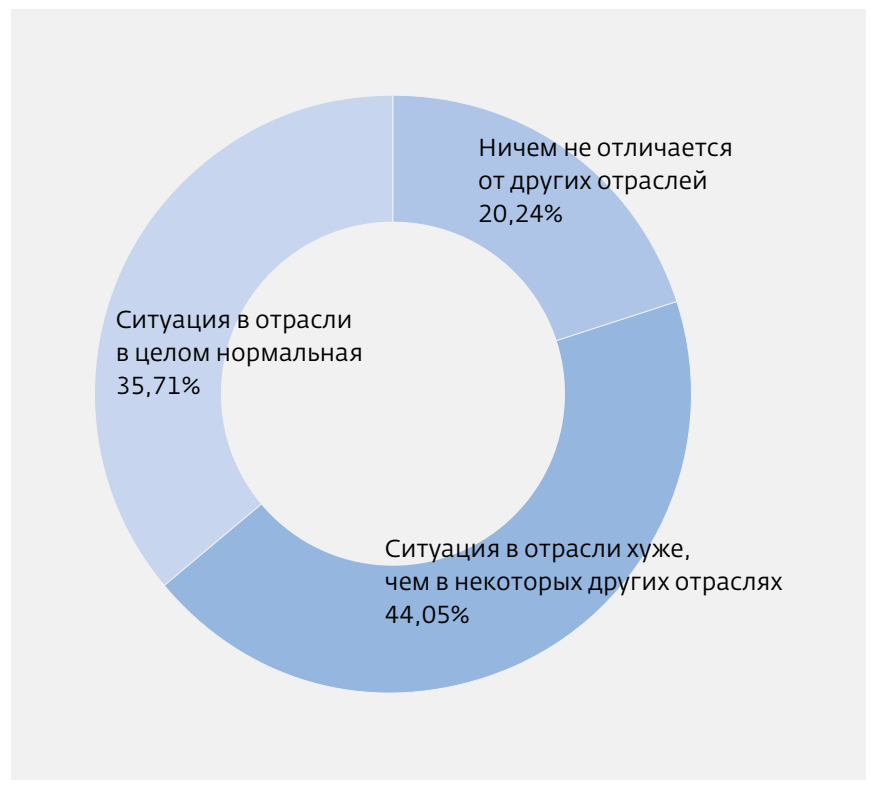

\section{КРАТКИЙ АНАЛИЗ ИТОГОВ ИССЛЕДОВАНИЯ}

Благодаря достаточно широкой выборке респондентов, полученные в результате опроса данные показывают высокую степень корреляции с общемировыми и всероссийскими тенденциями и закономерностями [2]. Тем не менее в ряде случаев обнаруживаются проблемные вопросы для организаций, носящие системный характер, а иные ответы на вопросы позволяют установить отсутствие широко распространенных в других отраслях промышленности сложностей. Оба типа отклонений требуют особого внимания и выявления причин данной отраслевой специфики.

Так, например, было установлено, что в большинстве случаев оплата труда молодых специалистов находится на более низком уровне, чем считают необходимым сами представители организаций. Данный факт может быть связан с достаточно высоким уровнем кредиторской задолженности организаций отрасли, снижающим общую рентабельность деятельности и вынуждающим экономить на трудовых ресурсах, в особенности на сравнительно низкоквалифицированных, таких как недавно закончившие образовательные учреждения специалисты. Вторым фактором, сдерживающим возможности по повышению уровня оплаты труда, является то, что основным источником доходов подавляющего большинства организаций отрасли является выполнение государственного оборонного заказа. Стараясь уложиться в действующие нормативы затрат, организации зачастую вынуждены снижать объем фонда оплаты труда.

Стоит отметить еще одну причину, по которой организации устанавливают своим молодым сотрудникам уровень заработной платы ниже собственных ожиданий - низкий уровень подготовки специалистов. Данный факт был также подтвержден в ходе данного исследования. Лишь каждый десятый респондент считает возможным работу со вчерашними выпускниками без прохождения ими

Рис.18. Характеристика радиоэлектронной промышленности 
дополнительного обучения, а порядка 40\% участников опроса недовольны качеством знаний и навыков, которые дают российские образовательные учреждения. Как результат, многие организации вынуждены выделять ресурсы на дополнительную подготовку новых сотрудников или направлять их на курсы повышения квалификации.

Таким образом, можно сделать вывод, что руководство организаций установило определенную градацию по уровню зарплат, которая не всегда совпадает с ожиданиями кандидатов на трудоустройство. Новые сотрудники, которые приходят трудоустраиваться, вынуждены либо соглашаться с условиями компании, либо продолжать дальнейший поиск. В этом случае молодые специалисты, которые соглашаются на условия работодателя, делают это в ряде случаев от неизбежности или из-за отсутствия достойного выбора.

В нынешних экономических условиях проблемы с трудоустройством испытывают многие категории специалистов, но особенно трудно найти достойную работу выпускникам вузов и специалистам без опыта работы. В таких случаях, как правило, критерий уровня дохода смещается на второе место и молодые специалисты соглашаются на работу ради получения хорошего трудового опыта и практики, чтобы повысить свою стоимость на рынке труда.

Этими причинами можно объяснить ситуацию, что несмотря на сотрудничество с вузами, программы повышения квалификации и создание условий, которые, по мнению большинства руководителей организаций, являются привлекательными для молодых специалистов, по факту примерно в половину организаций устраивается менее 10\% выпускников.

Возможность дополнительного образования за счет работодателя также не всегда может рассматриваться в качестве мотивирующего инструмента. С одной стороны, если работодатель может взять на себя расходы по обучению молодых кадров по программе второго высшего образования, курсов повышения квалификации или других программ, которые могут повышать ценность специалиста для других работодателей, то такая мера может привлечь молодежь в отрасль. Но тогда крайне важным шагом для работодателей должен быть поиск решений, которые позволят удержать уже подготовленных специалистов в организации. В противном случае "взращенные" молодые кадры, которые пришли в отрасль на невысокую зарплату ради получения хорошего трудового опыта, получив его, уйдут в другие организации или в другие сферы деятельности.

Программы, которые применимы лишь в рамках данной конкретной организации для выполнения узкоспециализированных профессиональных обязанностей, не могут в полной мере считаться мотивирующим фактором для большинства сотрудников.

Проблемы российского образования хорошо известны, и за последние годы ситуация не сильно изменилась. По-прежнему образовательные программы, которые сегодня существуют в большинстве вузов, ориентированы на устаревшие требования к специальностям и не обеспечивают должное внимание вопросам получения практических навыков. Наука развивается своим собственным путем и, как правило, редко находит эффективные пересечения с реальными секторами промышленности. Это системная проблема, которая должна решаться на более высоком уровне.

Для повышения эффективности и качества образования необходима тесная связь работодателей с вузами. Некоторые образовательные и научные заведения делают шаги по решению данной проблемы, но для качественного скачка необходимо, чтобы это явление стало массовым.

Значительное число респондентов указывает на то, что ситуация в радиоэлектронной отрасли хуже, чем в других отраслях. Данный пессимизм, существующий несмотря на высокие темпы роста выручки в радиоэлектронной промышленности, может быть обусловлен сложностями с привлечением высококвалифицированных специалистов, закупкой иностранного технологического оборудования и комплектующих, а также опасениями респондентов относительно снижения объемов государственного оборонного заказа в будущем.

Тем не менее в последние годы конкурс на инженерных и технических специальностях в вузах постоянно повышается. Также отмечается постепенное увеличение доли молодых специалистов в отрасли в возрастной категории от 20 до 35 лет, что свидетельствует о росте престижа радиоэлектронной промышленности в качестве работодателя. Но вместе с тем необходима системная работа всех участников отрасли для решения структурных проблем в области подготовки кадров и привлечения наиболее перспективных специалистов.

\section{ЛИТЕРАТУРА}

1. Фомина А. Кто двигает электронику: мужчины или женщины? // ЭЛЕКТРОНИКА: Наука, Технология, Бизнес. 2017. № 6 (00166). C. 136-137.

2. Фомина А.В., Французова В.В., Корначев Д.В. Формирование национальной модели поддержки отечественного производителя радиоэлектронной продукции на основе международного опыта // Экономические стратегии. 2016. № 3 (137). С. 16-25. 